\title{
IN VITRO STUDY OF THE BRONCHORELAXATION EFFECT OF COPTOSAPELTA FLAVESCENS KORTH. ROOT'S EXTRACT AND FRACTIONS
}

\author{
KHEMASILI KOSALA ${ }^{1,4 *}$, MOCH. ARIS WIDODO ${ }^{2}$, SANARTO SANTOSO ${ }^{3}$, SETYAWATI SOEHARTO ${ }^{2}$ \\ ${ }^{1}$ Doctoral Program of Medical Sciences, Faculty of Medicine, Brawijaya University, Jl.Veteran, Malang, Indonesia. ${ }^{2}$ Department of \\ Pharmacology, Faculty of Medicine, Brawijaya University, Malang, Indonesia. ${ }^{3}$ Department of Microbiology, Faculty of Medicine, Brawijaya \\ University, Malang, Indonesia. ${ }^{4}$ Department of Pharmacology, Faculty of Medicine, Mulawarman University. Jl. Kerayan Kampus Gunung \\ Kelua, Samarinda, Indonesia. Email: khemasili_k@yahoo.com
}

Received: 10 January 2019, Revised and Accepted: 15 February 2019

\section{ABSTRACT}

Objective: This study aimed to compare the bronchorelaxation effect of the methanol extract, hexane fraction, ethyl acetate fraction, and methanol fraction of Coptosapelta flavescens Korth. roots (CFRs) on the isolated bronchial rings of guinea pig.

Methods: Research design was experimental in which a 4-mm long bronchus of a male guinea pig was kept in an isolated organ bath containing Krebs-Henseleit solution at $37^{\circ} \mathrm{C}, \mathrm{pH} 7.4$, and flooded with carbogen gas. The bronchial ring was precontracted with methacholine and then given six doses of $C$. flavescens Korth. root's methanol extract (MECFR) solution cumulatively. The extract's solvent $10 \%$ dimethyl sulfoxide ethanol was used as negative control. This procedure was then repeated using CFRs hexane fraction (HFCFR) solution, CFRs ethyl acetate fraction (EAFCFR), and CFRs methanol fraction (MFCFR).

Results: The bronchorelaxation effect of MECFR, MFCFR, EAFCFR, and HFCFR is shown by their dose-response curves (DRCs) which are significantly different compared with the extracts solvent's DRC. The maximal efficacy $\left(\mathrm{E}_{\mathrm{max}}\right)$ of MFCFR was the same $(\mathrm{p}>0.05)$ as the MECFRs $\mathrm{E}_{\text {max }^{\prime}}$, but the EAFCFRs and HFCFRs $\mathrm{E}_{\max }$ were smaller $(\mathrm{p}<0.05)$ than the MECFRs $\mathrm{E}_{\max }$

Conclusion: The bronchorelaxation effect of the MECFR on the guinea pig's bronchial ring is similar to the CFRs methanol fraction, and is stronger than the CFRs ethyl acetate fraction and CFRs hexane fraction.

Keywords: Bronchorelaxation, Coptosapelta flavescens Korth. root, Extract, Fractions.

(C) 2019 The Authors. Published by Innovare Academic Sciences Pvt Ltd. This is an open access article under the CC BY license (http://creativecommons. org/licenses/by/4. 0/) DOI: http://dx.doi.org/10.22159/ajpcr.2019.v12i4.31401

\section{INTRODUCTION}

Coptosapelta flavescens Korth. is a liana plant from Rubiaceae family. In Kalimantan, it is known as Akar Tambolekar or Akar Merung [1] or Akar Manuran [2]. It is used in ethnobotany as herbs to overcome cough and shortness of breath [3]. Shortness of breath is a clinical symptom of bronchoconstriction that occurs in people with asthma or chronic obstructive pulmonary disease [4,5]. Therefore, it is presumed that $C$. flavescens Korth. root (CFR) has bronchorelaxation effect by relaxing the contracting bronchial smooth muscles. In a previously unpublished study, it has been shown that the CFRs methanol extract (MECFR) has a bronchorelaxation effect through the stimulation of the beta- 2 adrenergic receptors. It has been known that MECFR contains secondary metabolites of saponins, polyphenols, triterpenoids, steroids, and anthraquinone; CFRs hexane fraction (HFCFR) contains anthraquinone and steroids; CFRs ethyl acetate fraction (EAFCFR) contains polyphenols, terpenoids, and anthraquinone; and CFRs methanol fraction (MFCFR) contains saponins, polyphenols, and terpenoids [6]. Secondary metabolites in plants contribute to the plants' pharmacological effects [7]. Thus, the secondary metabolites in CFR which are responsible for CFRs bronchorelaxation effect can be found by studying the bronchorelaxation effect of different CFR's fractions. While there were existing studies on MECFR bronchorelaxation effect on guinea pig's bronchial ring precontracted with methacholine, there are no data available on the bronchorelaxation effect of any CFRs fraction, whether polar or non-polar. Therefore, the aim of this study was to compare the bronchorelaxation effect of MECFR with CFRs hexane (non-polar) fraction, CFRs ethyl acetate (semi-polar) fraction, and CFRs methanol (polar) fraction. The study was conducted using the isolated bronchial ring of guinea pigs [8].

\section{MATERIALS AND METHODS}

\section{Materials}

C. flavescens Korth. roots (CFRs) were collected from Paser Regency of East Kalimantan Province. Identification was done by the taxonomist of the Forestry Faculty of Mulawarman University with an identification letter no. 09/UN17.4.3.08/LL/2014. The roots were sorted and washed in running water then cut into small pieces and dried in an oven at $60^{\circ} \mathrm{C}$ until the water content was $<10 \%$, then ground into powder. Methanol, $\mathrm{n}$-hexane, and ethyl acetate for extraction were purchased from SigmaAldrich distributor in Surabaya. Ingredients to make Krebs-Henseleit solution such as $\mathrm{NaCl}, \mathrm{KCl}, \mathrm{MgSO}_{4}, \mathrm{Na}_{2} \mathrm{HPO}_{4}, \mathrm{KH}_{2} \mathrm{PO}_{4}, \mathrm{CaCl}_{2}$, and glucose were purchased from a distributor in Surabaya. Carbogen gas $(95 \%$ $\mathrm{O}_{2}$ gas and $5 \% \mathrm{CO}_{2}$ gas) was purchased from PT Murni Gas Raya in Samarinda.

Test animals were 3-4-month-old male guinea pigs weighing 350$400 \mathrm{~g}$ obtained from Pharmacology Laboratory, Faculty of Medicine of Mulawarman University, Samarinda; ethical approval was obtained from Medical Ethics Committee, Faculty of Medicine of Mulawarman University.

Tools for bronchorelaxation assay were six chambers isolated organ bath, octal bridge amplifier, Power Lab/16SP digital recorder, isometric transducer, $\mathrm{pH}$ meter, tweezers, and surgical scissors.

\section{Preparation of MECFR}

Dried and ground simplicia of CFR (300 g) were macerated in $1.5 \mathrm{l}$ of proanalytic methanol solution and shaken continuously for 3 day. The filtrate was collected and the residue was macerated further in pro-analytic 
methanol solution. This procedure was repeated until the resulting filtrate became colorless. All the collected filtrates were then evaporated using a $50^{\circ} \mathrm{C}$ vacuum rotavapor. The condensed mass obtained was heated in an oven $\left(50^{\circ} \mathrm{C}\right)$ to obtain a dry extract with a moisture content of $<10 \%$.

Preparation of hexane, ethyl acetate, and methanol fractions of CFR The CFR fractions were made using the same procedure as with MECFR, in a successive manner [9] by first using the non-polar solvent $\mathrm{n}$-hexane. The concentrated extract obtained from the n-hexane filtrate was the HFCFR. The residue subsequently was aerated in the open air for $24 \mathrm{~h}$ to evaporate out the remaining n-hexane. Second, the semipolar solvent ethyl acetate was added using the same procedure as above. The concentrate obtained from the ethyl acetate filtrate was the EAFCFR. The residue was then aerated in the open air to evaporate out the remaining ethyl acetate solvent, and subsequently, the polar solvent methanol was added according to the above procedure. The concentrated extract obtained from the methanol filtrate with water content $<10 \%$ was the MFCFR. Each of the MECFR, HFCFR, EAFCFR, and MFCFR was weighed to calculate their yields.

\section{Guinea pig's bronchial preparation}

Male guinea pigs (Cavia porcellus), 3-4 months old (350-400 g), were fasted for $12 \mathrm{~h}$ and subsequently anesthetized and sacrificed by cervical dislocation. Surgery was done by opening the abdomen and thorax until the lungs were visible. After dissecting the lungs and trachea, they were placed in a Petri dish containing Krebs-Henseleit solution. Attached fats and connective tissue were removed from the bronchial segments, and it was then cut into a length of $4 \mathrm{~mm}$ and put into an organ bath filled with $10 \mathrm{ml}$ Krebs-Henseleit solution, maintained at $37^{\circ} \mathrm{C}, \mathrm{pH} 7.4$, and flooded with carbogen gas. Bronchial ring arrangement was in accordance with what has been described by Albuqueque [8]. One end of the bronchial ring was connected with a stainless steel tissue holder and the other end was mounted on an isometric transducer with a tone of $1 \mathrm{~g}$ and connected to a Power Lab recording device, AD Instrument with Program Chart v.5. Changes in bronchial contractility on the computer were recorded in $\mathrm{g}$.

\section{Bronchorelaxation effect of MECFR on bronchial ring assay}

Before treatment, the bronchial ring was equilibrated in Krebs-Henseleit solution for $60 \mathrm{~min}$, and every $15 \mathrm{~min}$, the solution was replaced with fresh solution. After the equilibrium state had been achieved, single dose amounted to $20 \mu \mathrm{l}$ of $10^{-3} \mathrm{M}$ methacholine solution was administered and maximum contraction was reached. After plateau had been reached, the extract solvent $10 \%$ dimethyl sulfoxide (DMSO) ethanol was given cumulatively in increasing dosages every $100 \mathrm{~s}$ and then left undisturbed for $10 \mathrm{~min}$. Subsequently, the solution was replaced with new Krebs-Henseleit solution for 3 times every $10 \mathrm{~min}$. The treatment was continued again with precontraction using a single dose of $20 \mu \mathrm{l} \mathrm{of} 10^{-3} \mathrm{M}$ methacholine solution until the maximum contraction was reached, and then, MECFR solution was given cumulatively in increasing dosages of six different concentrations every $100 \mathrm{~s}$ and then left undisturbed for $10 \mathrm{~min}$.

\section{Bronchorelaxation effect of HFCFR, EAFCFR, and MFCFR on} bronchial ring assays

The procedure for the bronchorelaxation effect assay for each HFCFR, EAFCFR, and MFCFR was similar with the bronchorelaxation effect assay for MECFR on the isolated bronchial ring of guinea pig which was contracted with methacholine, using 10\% DMSO ethanol solvent as the negative control (NC).

\section{Calculation of the percentage of relaxation}

The bronchial ring's percent of relaxation was calculated using the following equation:

$$
\% \text { Relaxation }=\frac{\text { Relaxation response }(\mathrm{g})-\text { response of NC }(\mathrm{g})}{\text { Max precontration response }(\mathrm{g})} \times 100
$$

Then, the dose-response curve (DRC) was made by plotting the negative log of extract or fraction concentration on X-axis and bronchial ring's percentage of relaxation on Y-axis. The maximum efficacy $\left(\mathrm{E}_{\mathrm{max}}\right)$ was obtained from the maximum percentage of relaxation.

\section{Statistical analysis}

The data obtained were presented in the mean \pm standard error of the mean (sem). Percentage of relaxation from all six concentrations and $\mathrm{E}_{\max }$ from the DRC of MECFR, HFCFR, EAFCFR, MFCFR, and NC were analyzed with Sigma plot 12.5 one-way ANOVA, followed by the Tukey test. $\mathrm{p}=0.05$ or less was considered to be statistically significant.

\section{RESULTS}

Yield from methanol extract, hexane fraction, ethyl acetate fraction and methanol fraction of CFR

Table 1 shows the MECFR yield from $300 \mathrm{~g}$ of CFR simplicia and HFCFR, EAFCFR, and MFCFR yield from $667 \mathrm{~g}$ of CFR simplicia. The largest yield was obtained from MECFR $(21.94 \%)$, while the least yield was from hexane fraction (HFCFR) and ethyl acetate fraction (EAFCFR) at only $4 \%$.

Bronchorelaxation effect of MFCFR, EAFCFR, HFCFR, and MECFR on guinea pig's bronchial rings precontracted with methacholine Fig. 1 shows the relaxation effect on bronchial rings precontracted with $2 \mu \mathrm{M}$ of methacholine; then, each was given MFCFR, EAFCFR, HFCFR, MECFR, and the extract's solvent, 10\% DMSO ethanol, at cumulative doses. DRC of MFCFR, EAFCFR, HFCFR, and MECFR on Fig. 1 showed that as the concentration of extract or fractions became larger, the bronchial ring's percentage of relaxation increased. The percentage of relaxation for each of the fractions and extract was larger and significantly different $\left(\mathrm{p}<0.05^{*}\right)$ when compared to the NC, the extract's solvent; this showed that MFCFR, EAFCFR, HFCFR, and MECFR had bronchorelaxation effect and they were not influenced by the extract's solvent.

Fig. 1 also shows the maximum efficacy $\left(E_{\max }\right)$ of MFCFR, EAFCFR, HFCFR, and MECFR. The $\mathrm{E}_{\text {max }}$ of MFCFR $(-136.63 \pm 14.31 \%)$ was not significantly different $(p>0.05)$ compared with the $E_{\max }$ of MECFR $(-146.48 \pm 21.03 \%)$. The $\mathrm{E}_{\text {max }}$ of EAFCFR $(-76.74 \pm 4.68 \%)$ and HFCFR $(-80.01 \pm 6.68 \%)$ was smaller and significantly different compared with the $\mathrm{E}_{\max }$ of MECFR with $\mathrm{p}<0.05^{* *}$. The $\mathrm{E}_{\max }$ of EAFCFR was similar to the $\mathrm{E}_{\max }$ of HFCFR ( $\left.p>0.05\right)$. This showed that the bronchorelaxation effect of EAFCFR and HFCFR was similar but were weaker compared with MECFR and MFCFR. It could also be interpreted that among the extract and fractions, the bronchorelaxation activity of MECFR and MFCFR was the strongest.

\section{DISCUSSION}

The study's result shows that the bronchorelaxation effect of MECFR and MFCFR is of similar strength. In another unpublished study, MECFR has bronchorelaxation effect through stimulation of the beta- 2 adrenergic receptors; MECFR acts as beta- 2 agonist which stimulates beta-2 adrenoceptors which are part of the G-proteincoupled receptors group with $G_{s}$ alpha subunit. Beta-2 adrenoceptor coupled with $\mathrm{G}_{\mathrm{s}}$ protein stimulates adenylyl cyclase and produces second messenger cyclic adenosine monophosphate (cAMP) [10]. In the airways, cAMP will reduce intracellular $\mathrm{Ca}^{2+}$ concentration and activates protein kinase A resulting in the inactivation of myosin lightchain kinase (MLCK) and activation of ML-chain phosphatase (MLCP). MLCP activation will prevent the binding of actin and myosin which leads to smooth muscle relaxation. The decrease in intracellular $\mathrm{Ca}^{2+}$

Table 1: Yield from CFR extract and fractions

\begin{tabular}{lll}
\hline Extract/fraction name & Obtained weight $\mathbf{( g )}$ & Yield (\%) \\
\hline MECFR & 65.84 & 21.94 \\
HFCFR & 26.72 & 4.00 \\
EAFCFR & 27.29 & 4.09 \\
MFCFR & 79.80 & 11.96 \\
\hline
\end{tabular}




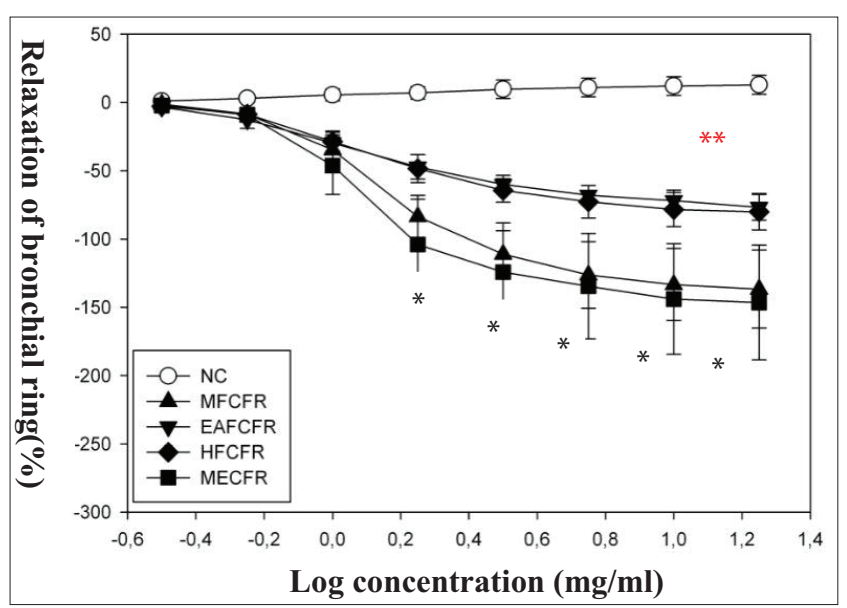

Fig. 1: The DRC of MFCFR, EAFCFR, HFCFR, and MECFR on guinea pig's bronchial ring precontracted with methacholine. Data presented as mean \pm standard error of mean from $n=6 .{ }^{*} p<0.05$ significantly different compared to negative control. ${ }^{* *} \mathbf{p}<0.05$ significantly different compared to MECFR

concentrations also causes a reduction in Ca-calmodulin binding such that contraction does not occur $[11,12,13]$. Other mechanisms that can affect bronchorelaxation are non-adrenergic non-cholinergic receptor pathway inhibitor, calcium channel antagonist, potassium channel activator, and epithelium-derived relaxing factors such as nitrite oxide and prostaglandin E2 [13,14].

Research's result also shows that MECFR and MFCFR have stronger bronchorelaxation effect on bronchial ring precontracted with methacholine, compared with HFCFR and EAFCFR. This result correlates with the active compound or secondary metabolite content in each extract and fraction. It has been known that MFCFR contains polyphenol, terpenoid, and saponin; EAFCFR contains polyphenol, terpenoid, and anthraquinone; and HFCFR contains steroids and anthraquinone $[6,15]$. From other researches, it has been shown that polyphenol, terpenoid, saponin, and steroid in other plant's extracts have some effects on the receptor related to the airway smooth muscle relaxation. Examples are as follows: Thymoquinone, a terpenoid widely contained in the essential oil of Nigella sativa, protects guinea pigs against histamine-induced bronchospasm. The water extract of $N$. sativa relaxes the tracheal smooth muscle of guinea pig through beta-2 adrenoceptor stimulation [16]. $\gamma$-sitosterol, found in Mimosa pudica L., can relax the smooth muscles of histamine-induced tracheal rings of a guinea pig [17]. Quercetin, a polyphenol (flavonoid group) which is found abundantly in fruits and vegetables, has been reported to have relaxation effects on human's bronchial smooth muscle through the inhibition of acetylcholine and histamine-induced bronchial contraction. It also has effects in the relaxation of guinea pig's bronchus by increasing the rate of cAMP formation such that cAMP-dependent protein kinase is activated and inhibits MLCK through phosphorylation, resulting in the reduction in contraction [7].

There are other studies which have shown plant extracts containing other secondary metabolites in the presence of either polyphenol, terpenoid, saponin, or steroid, having the effect of relaxing airway smooth muscle such as the raw extracts of Spinacia oleracea L. seeds which contain phenol, saponin, steroid, and tannin compounds have bronchodilation effect on rabbit trachea samples which were contracted with carbachol and high dosages of $\mathrm{K}^{+}[18]$. The ethanol extracts of Limonia acidissima Linn. pulp which contain flavonoids, glycosides, saponins, tannins, alkaloids, polyphenol, and sterols have bronchodilatory and antiasthmatic effect on the tracheal chains of guinea pig [19]. Marmin, a coumarin derivative isolated from stem bark and the root of Aegle marmelos Corr., has the effect to inhibit the guinea pig tracheal chain contraction induced by a series of histamine concentration in a competitive manner [20]. The stem of Albizia lebbeck Benth., Fabaceae, which contains tannin, catechin, triterpenoid, and albiziasaponin $\mathrm{A}, \mathrm{B}$, and $\mathrm{C}$, has activities in the protection against histamine- and acetylcholine-induced bronchoconstriction on some of the test animal models, as they have exhibited relaxation of smooth muscles, antihistamine, and antispasmodic activities. The extract of Balanite saegyptiaca Delile. and Zygophyllaceae (Balanitaceae) fruits, which contains steroidal saponin, coumarin, organic acid, balagyptin, balanitin-3 (spirostanol glycoside), balanitin-6 and 7, and other diosgenyl saponin and flavonoid, exhibits bronchodilation effect due to the presence of steroidal saponin [21].

Therefore, similarly applied to this research, the secondary metabolite in MECFR such as polyphenol, saponin, triterpenoid, and steroid has bronchorelaxation activities. The difference in strength of bronchorelaxation effects shown by the MFCFR, EAFCFR, and HFCFR could be affected by the type and quantity of the secondary metabolites in each fraction. From the extraction and fractionation result, EAFCFR and HFCFR yield were the smallest at only $4 \%$ while MFCFR yield was $11.9 \%$ and MECFR has the highest yield at $21.9 \%$ (Table 1). Consequently, the quantities of secondary metabolites in the EAFCFR and HFCFR were lower compared with MFCFR and MECFR which also can affect bronchorelaxation effect.

Polyphenol, saponin, and terpenoid are similar types of the secondary metabolites within MFCFR and MECFR which have stronger bronchorelaxation effect than EAFCFR and HFCFR. Therefore, it can be postulated that the secondary metabolites in CFR responsible for the bronchorelaxation effects are polyphenol, saponin, and terpenoid.

\section{CONCLUSION}

The bronchorelaxation effect of the MECFR on guinea pig's bronchial ring is of similar strength with its methanol fraction and of higher efficacy than its ethyl acetate fraction and hexane fraction.

\section{ACKNOWLEDGMENT}

Our thanks to the Provincial Government of East Kalimantan who has funded this research and to the Faculty of Medicine of Brawijaya University for their support and guidance throughout the research period.

\section{AUTHORS' CONTRIBUTIONS}

Khemasili Kosala contributed in the design experiments, data collection and analysis, and manuscript writing; Moch. Aris Widodo was involved in research planning and supervision; Sanarto Santoso contributed in technical advisory and manuscript revision; and Setyawati Soeharto was involved in data analysis and interpretation.

\section{CONFLICTS OF INTEREST}

Authors declare that there are no conflicts of interest.

\section{REFERENCES}

1. Kosala K, Ismail S, Fikriah I, Magdaleni AR. In vitro exploration of vasodilation activity of the methanol extract of the Coptosapelta flavescens Korth stem. J Islamic Med Res 2017;1:10-4.

2. Ajiningrum PS. Valuation of the Potential of the Diverse Non-Timber Forest Products in the Local Communities of Dayak Lundayeh and Uma'lung at Malinau Regency, East Kalimantan. Thesis. Graduate Program, Program Study of Biology, Faculty of Mathematics and Natural Science. Depok: Indonesia University; 2011. p. 68.

3. Darusman LK. Final Technical Report, The Potential of Medicinal Plants to Support Sustainable Forest Management: Ecological, Economic, and Sociocultura. I Aspects, Bogor Indonesia; 2004.

4. Global Initiative for Asthma (GINA). Pocket Guide for Asthma Management and Prevention, A Pocket Guide for Health Professionals; Updated 2017. p. 11-6.

5. Ouedraogo N, Roux E. Physiology of airway smooth muscle contraction: An overview. J Pulm Respir Med 2014;4:6, 
6. Kosala K. Phytochemical and toxicity studies of Coptosapelta flavescens Korth root's extract and fractions through color reaction and brine shrimp lethality test. Molucca Med J Kedokteran Kesehatan 2015;8:98-104.

7. Wani SA, Iqbal H, Basir SF. Mechanism of flavonoids action in smooth muscle relaxation. World J Pharm Pharm Sci 2017;6:514-50.

8. Albuquerque AA, Carvalho MT, Evora PM, de Nadai TR, Celotto AC, Evora PR. In vitro reactivity (“organ chamber") of guinea pig tracheal rings methodology considerations. Ann Transl Med 2016;4:216.

9. Sahidin I. Understanding Natural Compounds: Chemical Formation and Grouping. Kendari Indonesia: Unhalu Press; 2012.

10. Barisione G, Baroffio M, Crimi E, Brusasco V. Beta-adrenergic agonists. Pharmaceuticals (Basel) 2010;3:1016-44.

11. Johnson M. Molecular mechanisms of beta(2)-adrenergic receptor function, response, and regulation. J Allergy Clin Immunol 2006;117:18-24.

12. Kasahara DI, Perini A, Lopes FD, Arantes-Costa FM, Martins MA, Nunes MP. Effect of salbutamol on pulmonary responsiveness in chronic pulmonary allergic inflammation in guinea pigs. Braz J Med Biol Res 2005;38:723-30.

13. Husori DI, Harahap U, Marianne M, Yuliasmi S, Patilaya P, Laila L. Preliminary study of ethanolic extract of poguntano (Picriafel-terrae lour.) leaves on $\beta_{2}$-adrenoceptors, histamine 1 receptors and muscarinic3 acetylcholine receptors on isolated guinea-pig tracheal. J Pharm Res 2017;11:1279-84.
14. Vieira AB, Coelho LP, Insuela DB, Carvalho VF, dos Santos MH, Silva PM, et al. Mangiferin prevents guinea pig tracheal contraction via activation of the nitric oxide-cyclic GMP pathway. PLoS One 2013;8:e71759.

15. Setiorini A. Detection of Secondary Metabolites with Antioxidant Effects in Coptosapelta flavescens Korth Root's Fractions through Thin Layer Chromatography Test. Faculty of Medicine, Mulawarman University Samarinda; 2015. p. 65.

16. Keyhanmanesh R, Gholamnezhad Z, Boskabady MH. The relaxant effect of Nigella sativa on smooth muscles, its possible mechanisms and clinical applications. Iran J of Basic Med Sci 2014;17:939-49.

17. Myint PP, Kyi MM, Myint SH, Ngwe DH. Investigation of phytochemical constituents and smooth muscle relaxation activity of various herbal plants in Myanmar. J Complement Altern Med Res 2016;1:1-10.

18. Asifa S, Mueen A, Madiha H, Alamgeer A, Safur RM. Pharmacological evaluation of antispasmodic and bronchodilator effects of Spinacia oleraceae L. Am J Phytomed Clin Ther 2017;5:13.

19. Mahapatra PK, Pradhan D. Relaxant effects of Limonia Acidissima Linn (pulp) on guinea pig tracheal chains and its possible mechanism (S). Int J Pharm Pharm Sci 2014;6:257-63.

20. Nugroho AE, Wibowo JT, Riyanto S. Marmin, a compound from Aegle marmelos Corr., relaxes the ovalbumin-induced contraction of trachea. Int J Pharm Pharm Sci 2012;4 Suppl 1:479-84.

21. Adesina SK, Johnny II, Olayiwola G. Plants in respiratory disorders anti-asthmatics: A review. Br J Pharm Res 2017;16:1-22. 